\title{
Gündelik Yaşamda Çocuklar ve Anne-Baba Arasındaki İskele Kurma Temelli Etkileşimler
}

\author{
Yrd. Doç. Dr. Emine Nihal AHİOĞLU LİNDBERG* \\ Kastamonu Üniversitesi, Eğitim Fakültesi, Eğitim Bilimleri Anabilim Dalı, \\ 37000 Kastamonu / Türkiye
}

\begin{abstract}
Özet
Bu çalışmada, alt sosyoekonomik düzeydeki anne-babalar ile 4-5 yaşlarındaki çocuklar arasındaki gündelik etkileşimlerdeki iskele kurma davranışları ve çocukların bunlara tepkilerinin tanımlanması amaçlanmıştır. Çalışma grubu, alt sosyoekonomik düzeyden yedi aileyi kapsamaktadır. Araştırmanın verileri "katılımcı gözlem" tekniği ile elde edilmiş ve "betimsel” olarak analiz edilmiştir. Analizler; etkileşimlerin sıklığı, etkileşim kişisi, anne-babanın kullandığı iskele kurma davranışları ve çocuğun bu etkileşimler sırasındaki davranış kategorilerini içermektedir. Annebabanın iskele kurma davranışları sözel strateji, doğrudan ya da elle yardım etme,

* Tel: +90 3662142312 / $119 \quad$ E-posta: nihal.lindberg@acdoc.eu

(C) 2012 Kalem Eğitim ve Sağlık Hizmetleri Vakfı. Bütün Hakları Saklıdır. ISSN: 2146-5606
\end{abstract}


model olma, görevi anne babanın tamamlaması olmak üzere dört başlık altında analiz edilmiştir. Ayrıca sözel stratejiler; dikkat çekme, dikkati görev üzerinde tutma, genel / özel nitelikli sözel açıklamalarda bulunma, geribildirim verme ve görevle ilgisi olmayan bir şey söyleme veya bir davranışta bulunma alt kategorileri temelinde analiz edilmiş̧ir. Çocuğun tepkileri ise dikkat etme, problemi çözmek için çaba gösterme, problemin çözümüne yönelik ipuçlarını ya da yönergeleri izleme/izlememe, problemin çözümüne yönelik sözlü ya da sözsüz yardım talebinde bulunma, problem üzerinde çalışmaktan vazgeçme olmak üzere beş kategoride analize alınmıştır. Çalışmada gözlenen 107 iskele kurma temelli etkileşimin daha çok anneler ile kurulduğu belirlenmiştir. Anne-babalar "sözel stratejileri" diğer iskele kurma stratejilerinden daha fazla kullanmışlardır. Bunun yanında en fazla kullanılan sözel stratejinin dikkat çekme olduğu; bunu sırasıyla genel ya da özel nitelikli açıklamalar yapma ve olumsuz geribildirim verme stratejilerinin izlediği görülmüştür. Çocukların anne-babanın davranışlarına gösterdiği tepkilerin başında görevi çocuğun tamamlaması, problemi çözmesi gelmektedir. Bu tepkiyi çocuğun anne-babanın açıklamalarına ya da yönergelerine dikkat etmesi ve sonrasında da ipuçları/yönergeleri izlememe kategorileri izlemektedir.

Anahtar Kelimeler: Vygotsky; İskele kurma; Yakınsak gelişim alanı; Gündelik etkileşimler; Katılımcı gözlem.

\title{
Parent-Child Scaffolding Interactions in Daily Life
}

\begin{abstract}
In this research, daily interactions between 4-5 years old children and their parents coming from low socioeconomic status were studied. The goal was to define daily interactions between parents and children with 4-5 years old according to content of the cognitive themes of interactions. Seven families participated to the research. Participant observation technique was used for data gathering. The data was analyzed according to categories: with whom children interact; scaffolding behaviors of parents in cognitive based interactions and
\end{abstract}


finally children outcomes in these interactions. The analyses of parental scaffolding behaviors were included four themes as verbal strategy, direct support / help, modeling and complete the task without children involvement. The verbal strategies were analyzed to five subcategories as take attention, keep attention on task, make general / specific verbal explanations, give feedback and say / do something irrelevant to the task. Children' outcomes were analyzed to pay attention, endeavor to solve problem, to follow/not follow the cues related with problem solving, ask for help verbally or non-verbal, disclaimer to work on the task, completed task by her/himself. It was found that observed 107 interactions was started by mother. Parent used verbal strategies more than others. Mostly used verbal strategies were respectively taking attention, make general / specific verbal explanations, and give feedback. Children common outcome for the parents' behavior was to complete the task by their selves. The following outcomes were respectively paying attention to the explanations of parents and not following the cues related with problem solving.

Key words: Vygotsky; Scaffolding; The zone of proximal development; Daily interactions; Participant observation.

\section{Extended Summary}

\section{Purpose}

Broadly defined, scaffolding is the process by which tutors help plan and organize the activity of children so that they can execute a task that is beyond their current level of ability. Originally coined by Wood, Bruner and Ross (1976), the concept of scaffolding was proposed as a model to account for how certain types of social interaction facilitate children's development. In this research, parent-child scaffolding interac- 
tions were studied. The purpose of this study was to determine the scaffoldings of daily interactions between parent and children with 4-5 years old in detail. Moreover, this study addressed three research questions; the first of which was to determine amount of interactions and with whom children interact. The second aim was to define scaffoldings of parents in interactions. Finally, the last one was to identify the children outcomes in scaffolding interactions.

\section{Methods}

Participant observation technique based on qualitative research method was used for data gathering. Seven families with children whose age range was between four and five were visited at home and observed by the researcher 10 times. In those visits, the researcher took field notes on interactions of family members. The classifications of Wood, Bruner \& Ross (1976) and Mcnaughton \& Leyland (1990) for scaffoldings in these interactions were used to analyze data. So, the categories for analysis were following: with whom children interact; scaffolding behaviors of parents in cognitive based interactions and finally children outcomes in these interactions. The analyses of parental scaffolding behaviors were included four themes as verbal strategy, direct support / help, modeling and complete the task without children involvement. Adding to this, the verbal strategies were analyzed to five sub-categories as take attention, keep attention on task, make general / specific verbal explanations, give feedback and finally, say / do something irrelevant to the task. Children' outcomes were analyzed to pay attention, endeavor to solve problem, to follow/not follow the cues related with problem solving, ask for help 
verbally or non-verbal, disclaimer to work on the task, completed task by her/himself. The consistency of codings were 0.92 and inter-coder agreement was 0.87 in analysis process.

\section{Results}

In this research, the analyses on interactions were revealed that after 202 hours observations, 107 scaffolding interactions were defined. These interactions mostly were made with mother. It was seen that children preferred their mothers for daily-life problems such as dressing, reaching to glass on shelf etc. and their fathers for complex planned or structured problems like blocks design. During scaffoldings, parents used verbal strategies more than the other strategies like direct support, modeling. Moreover, parents were verbally directive and highly controlling (a negative scaffolding behavior) in scaffolding interactions. They tended to provide fewer questions but more information to children. Another, relatively important, scaffolding behavior was parents' effort to taking attention of children to the problem or subject. But this effort was not pursued throughout the task was completed or children were interested. In this progress, parents' explanations on problems were very abstract and complex, so the children generally gave up to study on problem. Regarding to modeling behaviors, parents generally provided a full demonstration of how to approach a problem before the children didn't make an effort on problem. This caused children not to follow parents' directives about problem. Then, the parents didn't do anything in these situations to motivate children to work on the task again. Children common outcome for the parents' behavior was to complete the task by their 
selves. The following outcomes were respectively paying attention to the explanations of parents and not following the cues related with problem solving.

\section{Discussion}

In this research, it was examined parent-child scaffolding interactions. Although mothers were lower educational level than fathers, it was seen that the mothers were more related with the scaffolding interactions than fathers. This can be explained each parent's role identity on childraising. In the study, it was found that parents mostly used "verbal strategies” than the others. However, since the parents' explanations were so abstract or not suitable for children cognitive development level, the children didn't show interest to the tasks or strive to solve problem by themselves. So, negative scaffoldings were observed than positive. This situation created an obstructive condition for children to remain in their zone of proximal development. Moreover, the feedbacks used were mostly negative and not supportive as providing to continue working on the task or problem. The other strategy used by parents was to complete the task or solve the problem by their selves instead to give opportunity to the children. Adding, direct support/help or modeling defined as optimal strategies in scaffolding were not used or not enough amount in parentchild scaffolding interactions. Since the children couldn't reach reference point to solve problem, they were not motivated to continue to the scaffolding interactions. 


\section{Conclusion}

Related with a task or problem, to support child to express his/her own plan, to motivate about it at beginning of interaction and then to provide guidance for evaluating, revising and re-organizing the plan across the interaction are important for development and learning. In scaffolding interactions, to support of children' involvement and cooperation are vital for subjectivity and internalization in learning, and then for development into the zone of proximal development (Vygotsky and Luria, 1994; Wertsch, 1997). This research showed that parents came from low socioeconomic status didn’t have effective and positive scaffolding behaviors. Instead, they used more verbal strategy but they didn't give so much feedback. They gave general or special explanations for the task or problem but they were not suitable or appropriate to the children' cognitive development level.

\section{Giriş}

Gelişim psikolojisinde kültürel-tarihsel yaklaşıma göre çocuk; hem kültürün yarattıklarını yetişkinler yoluyla kullanarak gelişmekte hem de bulunduğu bağlam içerisinde ya kendi kültürünü yaratmakta ya da var olan kültürü değiştirmektedir. Toplumdan bireye aktarımı içeren bu sürecin en önemli sorunu, değişimin ya da bu aktarımın "nasıl”" gerçekleştiğidir. Vygotsky (1978), aktarımın “yakınsak gelişim alanı” olarak tanımlanan bir mekanizma ile gerçekleştiğini belirtmektedir. Bu mekanizma, çocuğun bağımsız problem çözme becerisi olarak tanımlanan gerçek gelişim düzeyi ile problemi yetişkin rehberliği ya da daha yetkin akranlarla iş birliği yaparak çözebilmesi anlamına gelen potansiyel gelişimin 
ileri düzeyi arasındaki uzaklık olarak tanımlanmaktadır (Vygotsky, 1978, s.86). Chaiklin (2003) bu tanımın gelişim açısından önemli üç temel açıklayıcı varsayıma dayandığını belirtmektedir. Birinci varsayım olan "genellik" varsayımı, bir kişinin tek başına belli sayıda görevi başarabilirken, iş birliği ile daha çok sayıda görevi başarabileceği fikrine dayanmaktadır. İkinci varsayım, "potansiyellik” varsayımı, öğrenen kişinin özelliklerini, var olan gelişim potansiyelini ya da öğrenmeye hazır olma durumunu vurgulamaktadır. Üçüncü varsayım olan “yardım etme” (assistance) varsayımı ise yetişkinin, öğretmenin ya da daha yetenekli akranın çocukla nasıl etkileşime girmesi gerektiği üzerinde durur ve kimi zaman bütün olarak kavramı tanımlayıcı bir özellik olarak değerlendirilir (Chaiklin, 2003). Ancak bu son durumda asıl vurgulanan, çocuğa yardım eden kişinin özellikleri değil çocuğun öğrenme ve gelişiminde, bu yardımın ya da iş birliğinin ne anlama geldiği ya da içeriğidir.

Wood, Bruner ve Ross (1976), çocukla yetişkin arasındaki iş birliğinde yetişkin ya da daha yetkin akranların rolünü tanımlayıcı ve açıklayıcı bir metafor olarak iskele kurma (scaffolding) kavramını önermişlerdir. İskele kurma, başlangıçta öğrenen kişinin kapasitesinin üzerinde olan bir görevle bağlantılı tüm özelliklerin öğretici, yetenekli bir yetişkin ya da akran gibi bir başka kişi tarafindan kontrol edilmesi ve böylelikle onun sadece bu özelliklere dikkatinin çekilerek kendi yetenek sınırları içerisinde görevi tamamlaması biçiminde açıklanır. Bu kavram, Vygotsky’nin yakınsak gelişim alanı fikrine dayanmaktadır. Mercer ve Fisher (1993), yakınsak gelişim alanı ile iskele kurma arasındaki ilişkiyi açıklarken, yakınsak gelişim alanının potansiyel gelişim özelliklerinin ortaya çıkma- 
sını sağlayan "sorumluluğu paylaşma” yönünün, iskele kurma kavramının en önemli özelliği olduğunu belirtmektedir. "Sorumluluğu paylaşma”da önemli olan nokta, öğrenme ve gelişimde toplumsal etkileşimler ve bu etkileşimlerin karşılıklılı̆̆ı içeren doğasıdır. İskele kurma, temelde çocuğun var olan gelişim düzeyi ile çözemediği problem durumları ile karşılaştığında yaşadığı bilişsel zorlanmanın, yetkin bir başka kişi tarafindan kontrollü bir biçimde sunulması fikrine dayanmaktadır (Wood, Bruner ve Ross, 1976). Kontrol sağlama ve sorumluluk alma biçiminde kavramsallaştırılan iskele kurma sürecinde yetişkinin en önemli rolü, öğrenme çevresini düzenleme, kullanılan teknik ya da sembolik araçları tanıtma, görevin ortaya konmasını ve onun var olan bağlam içine yerleştirilmesini sağlama biçiminde özetlenir (Coltman, Petyaeva ve Anghilera, 2002).

Wood, Bruner ve Ross (1976) ile Mcnaughton ve Leyland'in (1990) iskele kurma temelli davranışlarla ilgili araştırmaları sonunda, anne ve babanın iskele kurma temelli davranışları, dört genel kategoride ele alınmaktadır. İlk genel kategori, sözel strateji olarak adlandırılmaktadır. Bu kategori, çocuğun dikkatini belli bir göreve ya da probleme çekme, dikkati o görev ya da problem üzerinde tutma, görev ya da problemle ilgili genel veya özel nitelikli sözel açıklamalarda bulunma, çocuğa olumlu/olumsuz geribildirim verme ve çocuğa görev ya da problemle ilgisi olmayan bir şey söyleme ya da bir davranışta bulunma özelliklerini içermektedir. İkinci genel kategori durum ya da problemle ilgili olarak doğrudan ya da elle yardım etme biçiminde tanımlanmaktadır. $\mathrm{Bu}$ genel kategori, anne ya da babanın belirli bir problem durumunda, problemi 
çözmeye yönelik çocuğa fiziksel yardımda bulunmayı önerdiği ya da bu yardımı yaptığı her durumu içermektedir. Üçüncü genel kategori, çocuğa çözümle ilgili model olmadır. Anne ya da babanın çocuğun hâlihazırda uğraştığı problemin çözümünü doğrudan çocuğa göstermesi biçiminde tanımlanmaktadır. Dördüncü genel kategori, görevi anne babanın tamamlaması ya da problemi çözmesidir. Bu kategori anne ya da babanın problemi kendisinin çözmesi ya da problemin çözümünü çocuğa anlatması biçiminde tanımlanmaktadır. Çocuğun etkileşim sırasındaki davranışları ise, her bir etkileşime yönelik tepkileri düzeyinde ve beş özelliğe göre ele alınmaktadır. İlk özellik, dikkat etmedir. Çocuğun anne ya da baba ile etkileşiminde ilgili nesne, olgu, durum ya da probleme dikkat etmesi biçiminde açıklanmaktadır. İkinci özellik çocuğun problemi çözmek için çaba göstermesidir. Bu özellik, çocuğun anne ya da babası ile etkileşiminde çözüm önerilerinde bulunmasını içermektedir. Üçüncü özellik, çocuğun problemin çözümüne yönelik ipuçlarını ya da yönergeleri izleme/izlememesini içerir. Dördüncü özellik, problemin çözümüne yönelik sözlü ya da sözsüz yardım talebinde bulunma biçimindedir. Son özellik ise çocuğun problem üzerinde çalışmaktan vazgeçmesidir.

Bir süreç olarak ele alındığında iskele kurma sırasında anne-baba ve çocuğun gösterdiği davranışlar, iş birliğinin yönünü ve sonucunu etkilemektedir. Araştırmalarda annelerin nesneler, eylemler ve kavramlar arasındaki ilişkileri vurgulayan sözel açıklamalarının çocukların öğrenmelerini kolaylaştırdığı bulunmuştur (Smith, Landry ve Swank, 2000; Fidalgo ve Pereira, 2005). Bununla birlikte Harrist ve Waugh (2002), Szechter ve Liben (2004) ve Salonen, Lepola ve Vauras (2007) anne- 
babaların, çocuklar için çok fazla dikkat gerektiren ya da çocukların gelişim özelliklerine uymayan sözel açıklamalarının, çocukların görevle ilgili performansını olumsuz yönde etkilediğini belirtmektedir. Bu tür bir etkileşimdeki en büyük sorun araştırmacılara göre, belirtilen türdeki açıklamalardan sonra çocuğun görev ya da problem çözümü üzerindeki dikkatinin devam etmemiş olmasıdır. Benzer biçimde Clarke-Stewart (1988) daha fazla yönlendirici ve kontrol edici öğretim stratejileri ile çocuğun çözüm konusunda çaba göstermesini engelleyici nitelikteki stratejilerin, çocuğun bilişsel olarak daha düşük düzeyde performans göstermesine neden olduğunu ifade etmektedir. Raver (1996), Robinson, Burns ve Davis (2009), özellikle alt sosyoekonomik düzey ailelerde, annenin "iş birliğini destekleyici" ve "karşılıklık”ı içeren davranışlarının, çocuğun probleme dikkat etmesi ve bu dikkatin görev boyunca devam etmesi açısından önemli olduğunu ortaya koymuştur. Buna ek olarak Nilholm ve Säljö (1996), Portes, Cuentas ve Zady (2000) ve Neitzel ve Stright (2004), tarafından yapılan çalışmalarda, hem etkileşimin kavramsal içeriğinin hem de etkileşim sırasında gösterilen davranışların annelerin eğitim düzeyinden etkilendiğini göstermektedir. Buna göre eğitim düzeyi yüksek annelerin, problemin çözümü sırasında çocuklarına daha fazla üst biliş bilgisi verdikleri, çocuğun problemin çözümü ile ilgili çabalarını destekledikleri, problemle ve bağlamla ilgili düzenlemeler yaparak çocuğun problemi çözmesine yardımcı oldukları ve son olarak çocuğun problem çözümünde aktif rol almasını sağladıkları belirlenmiştir. Bununla birlikte çalışmalarda, annelerin eğitim düzeyi düştükçe daha fazla yönlendirme ve kontrol içeren stratejiler kullandıkları ve çocukların proble- 
min çözümüne yönelik çabalarına ise çok az geribildirim verdikleri ortaya konmuştur.

Bu çalışma genel olarak, anne-baba çocuk arasındaki iskele kurma temelli etkileşimlerin, sosyoekonomik düzey ve eğitim düzeyi değişkenleri ile birlikte ele alındığında, Türk anne-baba ve çocuklar arasındaki gündelik etkileşimlerde nasıl ortaya çıktığı problemine odaklanmaktadır. Rogoff, Mistry, Göncü ve Mosier’in (1993) Vygotsky’nin sosyokültürel kuramı çerçevesinde ifade ettiği gibi, anne-baba-çocuk etkileşimlerinin içerik ve biçimi, kültürel farklılıklar göstermektedir ve bu farklılık ancak çocuğun bulunduğu toplumdaki değer ve inançlar yoluyla açılanabilir. Çünkü temelde bu iki değişken, paylaşılan inanç ve değerlerin gücünü ve bunların aile içerisinde ne düzeyde temsil ya da karşılık bulduğunu göstermesi açısından önemlidir. Ancak etkileşimlerin tam ve bütüncül bir anlayışla tanımlanabilmesi için, çocuğun bulunduğu/yaşadığı çevreye odaklı bir yaklaşımın yani gelişimin toplumsal bağlamı üzerinde durulması gerekmektedir. Bu doğrultuda, özellikle bilişsel gelişimin incelenmesi söz konusu olduğunda, günlük yaşamda öğrenmeye dayalı yetişkin rehberliğinin düzey ve içeriğinin belirlenmesi, çocuğun tek başına başardıklarından daha iyi, daha dinamik ve daha uygun bilgiler sağlayacaktır (Palincsar, 1998). Bu çalışmada amaç, 4-5 yaşlarındaki çocuklar ile annebabaları arasında ev ortamında ve günlük yaşamda kurulan toplumsal etkileşimlerdeki iskele kurma temelli davranışların niteliksel ve niceliksel özelliklerinin, bütüncül bir anlayışla tanımlanması ve incelenmesidir. $\mathrm{Bu}$ doğrultuda çalışmada yanıtı aranan sorular şunlardır: 
1. Alt sosyoekonomik düzeydeki anne-baba ve 4-5 yaşlarındaki çocukların gündelik yaşamdaki etkileşimlerinin sıklığı nedir ve çocuğun en fazla etkileşim kurduğu kişiler kimlerdir?

2. Alt sosyoekonomik düzeydeki anne-babaların gündelik yaşamlarında 4-5 yaşlarındaki çocuklarıyla etkileşimlerde kullandıkları iskele kurma temelli davranışlar nelerdir?

3. Alt sosyoekonomik düzeydeki anne-baba ve 4-5 yaşlarındaki çocukların gündelik yaşamdaki etkileşimlerinde anne ve babanın iskele kurma temelli davranışlarına karşı çocuğun gösterdiği tepkiler nelerdir?

\section{Yöntem}

\section{Çalışma Grubu}

Bu çalışma, alt sosyoekonomik düzeydeki yedi aile ile gerçekleştirilmiştir. Ailelerin sosyoekonomik düzeylerinin belirlenmesinde, öğrenim durumu ve aylık gelirleri temel alınmıştır. Annelerden 4'ü ilkokul, 3’ü ise ortaokul mezunudur. Babaların ise 4'ü lise, 3'ü ortaokul mezunudur. Ailelerin sosyoekonomik düzeylerinin belirlenmesinde Devlet İstatistik Enstitüsü (DİE, 2005) tarafindan aylık gelir harcamaları temel alınarak gerçekleştirilen yoksulluk analizleri esas alınmıştır. Annelerin hepsi ev hanımıdır, babalar ise farklı iş kollarında asgari ücretli işçi olarak çalışmaktadırlar. Anne babalardan hiçbiri, daha önce okulöncesi eğitime yönelik bir kurs ya da eğitim almamışlardır. Çalışmaya katılan annelerin yaş ortalaması 28, babaların ise 33'tür. Buna göre, iki ailede 4, iki ailede 3, iki ailede 2 ve bir ailede de 1 çocuk vardır. Gözlenen çocuklar dışındaki çocuklardan dokuzu ilköğretim öğrencisi iken biri 3 yaşında ve okula 
gitmemektedir. Çalışmaya dâhil edilen çocuklardan 4'ü kız, 3’ü erkektir. Çocukların yaş ortalaması ise $4,75^{\prime}$ tir.

\section{Verilerin Toplanması ve Analizi}

Betimsel nitelikli bu çalışmada veriler, "katılımcı gözlem” tekniği ile elde edilmiştir. "Katılımcı gözlem” tekniğine ilişkin en temel varsayım, davranışın kaçınılmaz bir biçimde bulunduğu bağlamla ilişkili olduğu biçiminde ifade edilmektedir (akt; Mackenzie, 1994). Gözlem süreci, birbirini takip eden üç aşamadan oluşmaktadır. Birinci aşama, mahalle muhtarı ve sağlık ocağı doktoru ile gerçekleştirilen ve mahallenin toplumsal özellikleri konusunda bilgi alınan görüşmeleri içermektedir. İkinci aşama, ailelere araştırmanın amacı ve süresi ile ilgili bilgi verilip araştırmaya katılmaya yönelik onayları alındıktan sonra gerçekleştirilen ortalama üç saatlik, ikişer tanışma ziyaretinden oluşmaktadır. Tanışma ziyaretleri, katılımcı gözlemde araştırmacının mümkün olduğunca bulunduğu bağlamın doğal üyeleri ile yakın bir ilişki kurmasının gerekliliğinden hareketle çalışmaya dâhil edilmiştir. Son aşama ise katılımcı gözlemci olarak araştırma verilerinin elde edildiği gözlemleri içermektedir.

Her aile, araştırma amacıyla her seferinde günün farklı zaman dilimlerinde ve kimi zaman da tüm gün olmak üzere 10 kez gözlemlenmiştir. Gözlem zamanlarının belirlenmesinde, anne babanın 4-5 yaşlarındaki çocuklarıyla en fazla birlikte olduğu günlük zaman dilimleri göz önüne alınmıştır. Bu nedenle her bir aileye yapılan ziyaretlerin gün içerisindeki zaman dilimi farklılık göstermektedir. Ailelerin herhangi bir kayıt cihazı kullanılmasını kabul etmemesi nedeniyle gözlemler araştırmacı tarafindan ayrıntılı notlar alınarak kaydedilmiştir. 


\section{Verilerin Analizi}

Analizler, iki aşamada gerçekleştirilmiştir. Birinci aşama, gözlem raporlarındaki tüm etkileşimlerin, etkileşim kişisinin ve sıklığının tanımlanmasını içermektedir. Gözlem raporlarındaki etkileşim örüntüleri, Eddowes ve Ralph (1998) tarafindan tanımlanan sinıflamaya göre incelenmiştir. İkinci aşama, anne babanın iskele kurmaya dayalı davranışları ve çocuğun bu davranışlarla ilgili tepkilerinin betimsel olarak analizini içermektedir. $\mathrm{Bu}$ aşamadaki analizlerde kullanılan kavram ve temalar için, Wood, Bruner ve Ross (1976) ile Mcnaughton ve Leyland'in (1990), iskele kurma ile ilgili araştırmaları temel alınmıştır. Buna göre anne-babaların iskele kurma temelli davranışları; sözel strateji, durum ya da problemle ilgili olarak doğrudan ya da elle yardım etme, çocuğa çözümle ilgili model olma, görevi anne babanın tamamlaması ya da problemi çözmesi olmak üzere dört başlık altında analiz edilmiştir. Bunun yanında sözel stratejiler de çocuğun dikkatini çekme, dikkati o görev/problem üzerinde tutma, genel/özel nitelikli sözel açıklamalarda bulunma, olumlu/olumsuz geribildirim verme ve görev/problemle ilgisi olmayan bir şey söyleme ya da bir davranışta bulunma olmak üzere beş alt başlıkta analiz edilmiştir. Çocuğa verilen geribildirimlerin niteliğinin öğrenmede önemli olduğu düşüncesinden hareketle, olumlu ve olumsuz geribildirimler analizlere ayrı ayrı dahil edilmiştir. Çocuğun davranışları ise, her bir etkileşime yönelik tepkileri düzeyinde ve beş alt kategoride analiz edilmiştir: dikkat etme, problemi çözmek için çaba gösterme, problemin çözümüne yönelik ipuçlarını ya da yönergeleri izleme/izlememe, problemin çözümüne yönelik sözlü ya da sözsüz yardım talebinde bulunma, problem üzerinde çalışmaktan vazgeçme. 
Kodlama süreci ile ilgili kodlamalar arası uyum için tüm gözlem kayıtlarının \%20'si bir başka araştırmacı tarafindan ve araştırmacının kendisi tarafından yeniden kodlanmıştır. Araştırmacının kendi kodlamaları arasındaki tutarlılık 0.92, bağımsız bir başka kişi ile araştırmacının kodlamaları arasındaki güvenirlilik ise 0.87 olarak belirlenmiştir.

\section{Bulgular}

Bu bölüm, etkileşimlerin sıklığı, çocuğun etkileşim kurduğu kişi, anne-babanın kullandığı iskele kurmaya dayalı davranışlar ve çocukların bu davranışlara gösterdikleri tepkilerle ilgili bulguları içermektedir. Anne ve babalarla ilgili bulgular ayrı ayrı ele alındığında çok sınırlı bilgi vereceğinden, bulgular anne-baba için birlikte verilmiştir.

Gerçekleştirilen toplam 202 saatlik gözlem sonunda, toplam 107 iskele kurma temelli etkileşim saptanmıştır. Yapılan analizlerde, etkileşimlerin 95'inin (\%89) annelerle ve 12'sinin (\%11) de babalarla kurulmuş olduğu belirlenmiştir. Anne-babaların etkileşimlerdeki iskele kurmaya dayalı davranışlarına ilişkin sonuçlar Tablo 1'de verilmiştir.

Tablo 1. Anne ve Babaların İskele Kurmaya Dayalı Davranışları

\begin{tabular}{lcc}
\hline & Frekans & Yüzde \\
\hline Sözel strateji & 153 & 75 \\
Doğrudan ya da elle yardım & 11 & 6 \\
Çözümle ilgili model olma & 16 & 8 \\
Görevi anne babanın tamamlaması, çözmesi & 23 & 11 \\
Toplam & $\mathbf{2 0 3}$ & $\mathbf{1 0 0}$ \\
\hline
\end{tabular}


Analizlerde anne ve babaların, iskele kurmaya dayalı etkileşimler sırasında sözel stratejileri (\%75) daha sık kullandıkları belirlenmiştir. Bu stratejiden sonra sırasıyla "görevi anne-babanın tamamlaması, çözmesi" (\%11), "çözümle ilgili model olma" (\%8) ve son olarak doğrudan ya da elle yardım (\%6) davranışları gelmektedir. Tablo 2'de anne-babalar tarafindan en fazla kullanılan sözel stratejiye ait alt kategorilerle ilgili bulgulara yer verilmektedir.

Tablo 2. Anne ve Baba Tarafindan Kullanılan Sözel Stratejiler

\begin{tabular}{lcc}
\hline & Frekans & Yüzde \\
\hline Dikkat çekme & 58 & 38 \\
Dikkati görev / problem üzerinde tutma & 11 & 7 \\
Genel / özel nitelikli açıklamalar yapma & 50 & 33 \\
Olumsuz geribildirim & 15 & 10 \\
Olumlu geribildirim & 11 & 7 \\
İlgisiz konuşma / davranış & 8 & 5 \\
Toplam & $\mathbf{1 5 3}$ & $\mathbf{1 0 0}$ \\
\hline
\end{tabular}

Tablo 2'deki sonuçlar, anne ve babaların en fazla kullandıkları sözel stratejinin dikkat çekme (\%38) olduğunu göstermektedir. Bu stratejiyi sırasıyla genel ya da özel nitelikli açıklamalar yapma (\%33) ve olumsuz geribildirim verme (\%10) stratejileri izlemektedir. Dikkati görev ya da problem üzerinde tutma (\%7) ve olumlu geribildirim verme stratejilerinin aynı düzeyde kullanıldığı, en az kullanılan stratejinin ise ilgisiz konuşma ya da davranış (\%5) olduğu belirlenmiştir. Anne ve babaların iskele kurmaya dayalı davranışlarına karşılık çocukların gösterdikleri tepkiler Tablo 3’te verilmiştir. 
Tablo 3. Çocukların Gösterdiği Tepkilere İlişkin Bulgular

\begin{tabular}{lcc}
\hline & Frekans & Yüzde \\
\hline Dikkat etme & 29 & 16 \\
Çözüm çabaları & 27 & 14 \\
İpuçları/yönergeleri izleme & 15 & 8 \\
İpuçları/yönergeleri izlememe & 28 & 15 \\
Sözlü/sözsüz yardım isteğinde bulunma & 26 & 13 \\
Görevi çocuğun tamamlaması, çözmesi & 41 & 22 \\
Vazgeçme & 24 & 12 \\
Toplam & $\mathbf{1 9 0}$ & $\mathbf{1 0 0}$ \\
\hline
\end{tabular}

Tablo 3’te de görüldüğü gibi çocukların anne-babanın davranışlarına gösterdiği tepkilerin başında görevi çocuğun tamamlaması, çözmesi (\%22) gelmektedir. Bu tepkiyi çocuğun anne-babanın açıklamalarına ya da yönergelerine dikkat etmesi (\%16) ve sonrasında da ipuçlar1/yönergeleri izlememe (\%15) kategorileri izlemektedir. Çocuğun çözüm konusunda çaba göstermesi (\%14), sözlü/sözsüz yardım isteğinde bulunma (\%13) ve görev/problem üzerinde çalışmaktan vazgeçmesi (\%12) izleyen diğer tepkilerdir.

\section{Tartışma}

$\mathrm{Bu}$ araştırma, alt sosyoekonomik düzey ailelerde, anne-baba ve 4-5 yaşlarındaki çocuklar arasındaki etkileşimlerde yer alan iskele kurma temelli davranışların tanımlanması amaçlanmıştır. Araştırma amacıyla yedi ailede toplam 202 saat gerçekleştirilen gözlemler sonunda 107 etkileşimde iskele kurma davranışına rastlanmıştır. Bu etkileşimlerle ilgili analizlerde, etkileşimlerin daha çok annelerle kurulduğu, babalarla ise 
sınırlı olduğu belirlenmiştir. Bu bulgu, Mcgowan ve Johnson’nın (1984) araştırmalarının bulguları ile çelişmektedir. Araştırmada geleneksel annelik davranışlarının, öğrenim düzeyinden etkilendiği, öğrenim düzeyi arttıkça daha az geleneksel tutumlar sergilendiği ve annenin çocukla bilişsel etkileşimlerinin miktarının bu durumdan olumlu yönde etkilendiği belirlenmiştir. Ancak yukarıda da belirtildiği gibi bu çalışmada annelerin, öğrenim düzeyleri babalardan daha düşük olmasına karşın çocukla daha fazla iskele kurma temelli etkileşimler kurdukları belirlenmiştir. Bu durum anne-babaların çocuk yetiştirme ile ilgili farklı rol kimliği tanımlamalarından, toplumun kültürel yapısı ve dolayısıyla ailenin kültürel özelliklerinden etkileniyor olabilir. Ancak bu çalışmada çocukların, günlük yaşama ilişkin nesne, durum ya da olgularla ilgili olarak daha çok anne ile etkileşime girmeyi tercih ederlerken, oyuncak bir maketin parçalarını birleştirme ya da bir resmi tamamlama gibi bir görevde baba ile etkileşime girmeyi tercih ettikleri belirlenmiştir. Bu bulgu, çocukların anne ile kurdukları etkileşimlerin niteliği ile ilgili de fikir vermektedir. Buna göre çocuk, var olan özellikleri ile yardımsız çözebileceği günlük yaşamı içeren problem durumlarında anneyi tercih etmekte ancak gerçekten yardıma ihtiyaç duyduğu, daha karmaşık, günlük yaşam ya da ev yaşamı dışındaki yapılandırılmış problem durumlarında babaya başvurmaktadır. $\mathrm{Bu}$ yönelim, babanın çocuğu yakınsak gelişim alanı içerisinde tutmaya yönelik duyarlılığını göstermesi açısından önemli bir ipucu niteliğindedir. Schaffer (akt; Chak, 2001) duyarlılı̆̆ı; yetişkinin çocuğun tepkilerine yönelik farkındalığı, tepkilerin çocuğun davranışlarına uygunluğu ve zamanlamasının doğruluğu biçiminde kavramsallaştırmaktadır. Bu doğrultuda çocuğun karmaşık ya da zorluk içeren problem durumlarında 
babayı tercih etmesinin nedeni, babanın çocuğun tepkilerine gösterdiği “duyarlılık” ile açıklanabilir. Bu durum çocuğun problem üzerinde çalışmaya devam etmesi ile ilgili tepkilerini de desteklemektedir.

Çalışmada, anne ve babaların iskele kurmaya dayalı etkileşimlerde çoğunlukla "sözel stratejiler" kullandıkları belirlenmiştir. Anne ve babalar belirli bir görev ya da problem durumu ile ilgili olarak çocuğun dikkatini görev ya da problem durumuna çekmekle birlikte dikkati sürdürmeye yönelik davranış ya da açıklamaları sınırlıdır. Dikkati sürdürme ya da görev/problem üzerinde tutma, iskele kurma açısından önemlidir. Çünkü bu durum anne ya da babanın, çocuğu görev ya da problem üzerinde çalışmaya cesaretlendirmesini ve böylelikle çocuğun çözüm konusunda çalışmaya devam etmesini, farklı yollar denemesini, aramasını ya da seçmesini gerektirir. Ancak etkileşimlerde bunun yerine daha çok genel veya özel nitelikli açıklamalar yapıldığı ve bunların, dikkati devam ettirmek amaçlı olmaktan çok, çözümü çocuğa göstermek ya da anlatmak amacıyla kullanıldığı gözlenmiştir. Diaz, Neal ve Amaya-Williams (1990) anne-babanın, çocukla etkileşimleri sırasındaki yönlendirmelerinde seçici olmaları gerektiğini, etkileşimlerinde düşük düzeydeki somut yönlendirmeler yerine yüksek düzeydeki kavramsal öğretimleri kullanmaları gerektiğini belirtmektedir. Ancak bu çalışmada da olduğu gibi, etkileşimlerde tek başına soyut sözel yönlendirmeler yapılması, iş birliğini olduğu kadar çocuğun yakınsak gelişim alanında kalmasını da engelleyici bir koşul yaratmaktadır. Sözel stratejilerle ilgili bir diğer bulgu, geribildirim kullanımının sınırlılığıdır. Kullanılan geribildirimler, daha çok olumsuz ve çocuğun problem ya da görev üzerinde çalışmaya devam 
etmesini engelleyecek niteliktedir. Bunun en önemli kanıtı, anne ya da baba tarafından verilen geribildirimlerden sonra çocuğun görev üzerinde çalışmaktan vazgeçmesidir. Bununla birlikte geribildirimler, çocuğun görevi tamamlama ya da problemi çözme ile ilgili güdülenmesinin devamı açısından önemlidir (Salonen ve ark., 2007; Hollenstein, Granic, Stoolmiller ve Snyder, 2004). Geribildirimlerle bağlantılı bir diğer bulgu, çocuğa görevle ilgili sorumluluğun verilmesindeki sınırlılıktır. Leseman ve Boom'un (1999) Almanya'da yaşayan Alman, Suriname ve Türk aileler ile yaptıkları çalışma, bu yöndeki bulguları desteklemektedir. Çalışmada, Türk annelerin görevi ya da problemi tanıtma ve çocuğun dikkatini çekme ile ilgili davranışlarının niteliksel olarak diğer gruptaki annelere göre daha düşük düzeyde olduğu belirlenmiştir. Buna ek olarak, Türk ve Suriname'li annelerin probleme uygun olmayan öğretim stratejilerini kullanım oranlarının, Alman annelerden daha fazla olduğu belirlenmiştir. Çalışmada Türk annelerin, yakınsak süreçlerle bağlantılı olarak, minimal düzeyde gerekli katılımı göstermedikleri ve belirli bir problem durumunda çözüm için gerekli duygusal desteği gösterme açısından Alman ve Suriname'li annelere göre daha yetersiz oldukları bulunmuştur.

Etkileşimler sırasında kullanılan diğer stratejilere bakıldığında, anne ve babaların sözel stratejiler dışında sıklıkla çocuk yerine görevi tamamladıkları ya da problemi çözdükleri belirlenmiştir. Ek olarak elle ya da doğrudan yardım ve model olma davranışlarının da etkileşimlerde yetersiz olduğu belirlenmiştir. Bu bulgu, Kerman ve Janes'in (1999) alt sosyoekonomik düzeydeki annelerle yaptıkları çalışmanın bulguları ile çelişmektedir. Çalışmada annelerin yapılandırılmış bir problem duru- 
munda, sözel açıklamalarda bulunmak yanında model olma stratejisini de sık kullandıkları, çocuğun bağımsız eylemlerini destekledikleri ve çocukların ilgilerine daha fazla dikkat ettikleri belirlenmiştir. Ancak bu çalışmadaki anne ve babalar daha önce de belirtildiği gibi sıklıkla sözel yönlendirmeler yapmakta, problemin çözümü ya da görevin tamamlanması ile çok fazla ilgilenmemektedirler. Wood, Bruner ve Ross (1976), etkili bir öğretim sürecinin hem sözel hem de sözel olmayan yardımı içermesi gerektiğini vurgulamaktadırlar. Hustedt ve Raver (2002) bu tür bir öğretimi, “optimal iskele kurma” biçimi olarak tanımlamaktadırlar. Buna göre, elle ya da doğrudan yardım ve model olma sözel olmayan optimal stratejiler iken, görevi ya da problemi yapılandırmacı bir anlayışla çözmeye dayalı sözel stratejiler (problemi çözmesine yardım edecek açıklamalarda bulunma, geribildirim verme) optimal sözel stratejiler olarak kabul edilmektedir. Bu çalışmada elde edilen bulgular, çocuk ile annebaba arasındaki iskele kurma temelli etkileşimlerin optimal iskele kurma düzeyinde olmadığını göstermektedir. Hoogsteder, Maier ve Elbers (1996), anne-babanın belirli bir problem çözümü sırasındaki etkileşim biçiminin ekonomik, toplumsal ve kültürel özelliklere bağlı olarak farklılaştığını belirtmektedir. Örneğin, didaktik etkileşim biçimi daha çok üst eğitim düzeyindeki anne-babalar tarafından kullanılmaktadır. Bu etkileşim biçimi, sonuçtan çok "süreç" odaklıdır. Bu çalışmada da ortaya konduğu gibi, alt sosyoekonomik ve eğitim düzeyindeki anne-babalar çocuklarıyla beceri temelli ve sonuca odaklı bir etkileşim kurmaktadırlar. Rogoff (1995) ve Wertsch’in (1997) de vurguladığı gibi, çocuğa belirli bir görevle ilgili olarak ne kadar çok sorumluluk verilirse, yani var olan özel- 
liklerini göstermesi için ne kadar firsat tanınırsa, çocukların özellikle bilişsel düzeydeki gelişimleri de o kadar desteklenmiş olacaktır.

Çocuğun bir görevin tamamlanması ya da problemin çözümü ile ilgili davranışlarında görülen dağılım, Vygotsky’nin (Vygotsky ve Luria, 1994) çocuğun problem çözümü sırasında gösterebileceği davranışlara ilişkin aşamalı tanımlaması ile paralellik göstermektedir. Bu aşamalardan ilki, çocuğun görev ya da problemle bağlantılı durum, olgu ya da nesneye dönük bir eylemde bulunmasıdır. Bu çalışmada çocukların görev ya da problem durumuna dikkat ettikleri belirlenmiştir. Buna bağlı olarak, çözümle ilgili çaba da göstermektedirler. Bu davranış, anne ve babanın dikkat çekmeye yönelik davranışları ile uyumludur. Problem çözümünün ikinci aşaması çocuğun problemin çözümü ile ilgili yardım isteğinde bulunmasıdır. Çalışmada çocukların problem çözümü için anne-babaya yöneldikleri ancak onlar tarafindan sunulan yardım ya da açılamaların yetersiz ya da sınırlı olduğu ve bunun çocuğun daha sonraki yönergeleri izlemesini engellediği belirlenmiştir. Kimi durumda ise, çocuklar görev ya da problem üzerinde çalışmaktan vazgeçmişlerdir. Bu durumun bir nedeni, etkileşimlerde sözel stratejilere diğer davranışlardan daha fazla yer veriliyor olması olabilir. Bununla birlikte daha önemli bir neden, çocuğun etkileşim sırasında anne ya da babadan çözüme yönelik plan oluşturmak konusunda yeterli desteği alamamış olmasıdır. Her iki neden birlikte ele alındığında çocuk, çözüme yönelik uygun başvuru noktalarını ya da planlarını elde edememekte ve bundan dolayı da etkileşime devam etmemektedir. Ancak bu çalışmanın bulguları, D. Wood, H. A. Wood ve Middleton'un (1978) belirli bir problem ya da görev durumunda anne- 
babanın bilişsel yönlendirmelerinin sınırlı ve düşük düzeyde olması gerektiğini ortaya koyan çalışması ile çelişmektedir. Çok fazla somut yönlendirme yapılması, çocuğun anne ya da babanın yönergelerini izlemesini ve görev üzerinde çalışmaya devam etmesini engellemekte; bir anlamda düşük düzeyde yönlendirme, çocuğun katılımını ve iş birliği yapma konusundaki istekliliğini olumsuz biçimde etkilemektedir.

\section{Sonuç}

Bu çalışmada, alt sosyoekonomik düzeydeki ailelerde çocukla kurulan iskele kurma temelli etkileşimlerin daha çok anne ile çocuk arasında gerçekleştiği belirlenmiştir. Belirlenen etkileşimlerle ilgili yapılan analizlerde anne-babaların iskele kurma yaklaşımına göre etkileşimlerde sözel stratejileri diğerlerinden daha fazla kullandıkları ortaya çıkmıştır. Öğretimde "iskele kurma” yaklaşımına göre, çocuğun potansiyel gelişim özelliklerini gösterebilmesi, etkileşimler sırasında görev ya da problemle ilgili sorumluluğun çocuk ve yetişkin ya da akran arasında paylaşılmasını gerektirmektedir. Etkileşimlerde çocuğun katılımının ve iş birliğinin desteklenmesi, karşılıklılık ve içselleştirmeyi dolayısıyla çocuğun yakınsak gelişim alanı içerisindeki gelişimi açısından önemlidir (Vygotsky ve Luria, 1994; Wertsch, 1997). Buna göre, belirli bir görev ya da problemle ilgili olarak etkileşimin başında, çocuğun kendi planını ifade etmesine fırsat tanımak, onu görevle ilgili olarak güdülemek ve etkileşim boyunca çözümünü sınamasını, değerlendirmesini ve gerekiyorsa planını yeniden gözden geçirmesini sağlayacak rehberliği yapmak, gelişim ve öğrenme açısından önemlidir. Ancak bu çalışmada anne-baba ve çocuk arasında bu tür bir iş birliği gözlenmemiştir. Aksine görev ya da problemin zorluk 
derecesinden bağımsız bir biçimde anne ya da babanın kendi seçimleri doğrultusunda etkileşimleri sınırlandırdıkları ve görevi kendilerinin tamamladıkları belirlenmiştir. Bunun özellikle çocuğun soru sorduğu, ek açıklama istediği ya da başarısızlık durumlarında daha sık kullanıldığının gözlenmiş olması, anne-baba ve çocuğun görev ya da probleme ilişkin tanımlarının ve amaçlarının da farklı olduğunu göstermektedir.

Araştırmanın ayrıntılara önem veren ve derinliğine gözlemi içeren yapısı, çalışılan aile sayısını sınırlandırmıştır. Bu durum, günlük yaşamdaki etkileşimler ve genel olarak alt sosyoekonomik düzeydeki ailelerin özellikleri hakkında pek çok bilgi sağlamakla birlikte, elde edilen verilerin genellenebilmesi için daha fazla sayıda aile ile çalışmak gerekmektedir. Çalışma ile ilgili bir diğer sınırlılık kullanılan yöntem ile ilgilidir. Çalışmada günlük etkileşimler sırasında gösterilen iskele kurmaya dayalı davranışlar, derinliğine ve katılımcı gözlemi içeren bir araştırma süreci içinde ele alınmıştır. Böylelikle iskele kurmaya dayalı davranışların belirli bir göreve ya da probleme göre değişip değişmediğinden çok, günlük yaşamda gösterilen olası tüm iskele kurmaya dayalı davranışların gözlenmesi mümkün olmuştur. Ancak okulöncesi dönemde kurulan iskele kurma temelli etkileşimlerin ve yönlendirmelerin niteliğinin, daha sonraki dönemde okul başarısı açısından önemli olduğu düşünüldüğünde, okul ile bağlantılı görev ya da problem durumlarındaki etkileşimlerin niteliksel özelliklerinin tanımlanmasını sağlayacak niceliksel çalışmalara da gereksinim vardır. Son olarak bu çalışmada, iskele kurma açısından önemli olan "duyarlılık" ya da "duygusal tarz" ile ilgili uygulamaların çocuğun etkileşimden elde edeceği yarar kadar sonraki davranışları açı- 
sından da önemli olduğu gözlenmiştir. Ancak çalışmanın amacı doğrultusunda bu yönde bir inceleme yapılmamıştır. Dolayısıyla çocukların etkileşimler sırasındaki davranışlarını ya da tepkilerini etkileyen bir değişken olarak bu konuda yapılacak çalışmalara da gereksinim vardır.

\section{Kaynakça}

Chaiklin, S. (2003). The zone of proximal development in Vygotsky's analysis of learning and instruction. A. Kozulin, B. Gindis, V. S. Ageyev, S. M. Miller (Düz.), Vygotsky's Educational Theory in Cultural Context içinde (39-65). New York: Cambridge University Press.

Chak, A. (2001). Adult sensivity to children's learning in the zone of proximal development. Journal for the Theory of Social Behaviour, 31 (4), 383-395.

Clarke-Stewart, K. A. (1988). Parents’ effects on children’s development: A decade of progress? Journal of Applied Developmental Psychology, 9, 41-84.

Coltman, P., Petyaeva, D. ve Anghilera, J. (2002). Scaffolding learning through meaningful tasks and adult interaction. Early Years, 22 (1), 39-49.

Devlet İstatistik Enstitüsü (2005). Gelir dă̆ılımı, tüketim ve yoksulluk: Yoksulluk analizleri.

http://www.tuik.gov.tr/PreTablo.do?tb_id=23\&tb_adi=Yoksulluk \%20Analizleri\&ust_id=7 adresinden 22 Mart 2005 tarihinde alınmıştır. 
Diaz, R. M., Neal, C. J. ve Amaya-Williams, M. (1990). The social origins of self-regulation. L.C. Moll (Düz.), Vygotsky and education. Instructional implications and applications of socio-historical psychology içinde (127-154). Cambridge: Cambridge University Press.

Fidalgo, Z. ve Pereira, F. (2005). Socio-cultural differences and the adjustment of mothers' speech to their children's cognitive and language comprehension skills. Learning and Instruction. 15, 1-21.

Eddowes, E. A. ve Ralph, K. S. (1998). Interactions for development and learning: Birth through eight years. New Jersey: Prentice Hall.

Harrist, A. W. ve Waugh, R. M. (2002). Dyadic synchrony: Its structure and function in children's development. Developmental Review, 22, 555-592.

Hoogsteder, M., Maier, R. ve Elbers, E. (1996). The architecture of adultchild interaction: Joint problem solving and the structure of cooperation. Learning and Instruction, 6 (4), 345-358.

Hustedt, J.T. ve Raver, C.C. (2002). Scaffolding in low-income motherchild dyads: Relations with joint attention and dyadic reciprocity. International Journal of Behavioral Development, 26 (2), 113119.

Hollenstein, T., Granic, I., Stoolmiller, M. ve Snyder, J., (2004). Rigidity in parent-child interactions and the development of externalizing and internalizing behavior in early childhood. Journal of Abnormal Child Psychology, 32, 595-607. 
Kerman, H. ve Janes, H.A. (1999). Adjustment across task in the maternal scaffolding in low income Latino immigrant families. Hispanic Journal of Behavioral Sciences, 21 (2), 134-153.

Leseman, P.P.M. ve Van den Boom, D.C. (1999). Effects of quantity and quality of home proximal processes on Dutch, Surinamese-Dutch and Turkish-Dutch preschoolers' cognitive development. Infant and Child Development, 8, 19-38.

Mackenzie, A. E. (1994). Evaluating ethnograpy: considerations for analysis. Journal of Advanced Nursing, 19, 774-781.

McGowan, R. J. ve Johnson, D. L. (1984). The mother-child relationship and other antecedents of childhood intelligence: A causal analysis. Child Development, 55 (3), 810-820.

Mcnaughton, S. ve Leyland, J. (1990). The shifting focus of maternal tutoring accross different difficulty levels on a problem solving task. British Journal of Developmental Psychology, 8, 147-155.

Mercer, N. ve Fisher, E. (1993). How do teachers help children to learn? An analysis of teachers' interventions in computer-based activities. Learning and Instruction, 2, 339-355.

Neitzel, C. ve Stright, A.D. (2004). Parenting behaviours during child problem solving: The roles of child temperament, mother education and personality, and the problem solving context. International Journal of Behavioral Development, 28 (2), 166-179.

Nilholm, C. ve Saljo, R. (1996). Co-action, situation definitions and sociocultural experience: An emprical study of problem solving in 
mother-child interaction. Learning and Instruction, 6 (4), 325344.

Palincsar, A. S. (1998). Social constructivist perspectives on teaching and learning. Online Annual Review Psychology, 49, 345-375.

http://arjournals.annualreviews.org/doi/abs/10.1146/annurev.psyc h.49.1.345?cookieSet=1\%20Social\%20constructivist\%20perspec tives\%20on\%20teaching\%20and\%20learning adresinden 24 Şubat 2007 tarihinde alınmıştır.

Pratt, M.W., Kerig, P., Cowan, P.A. ve Cowan, C.P. (1988). Mothers and fathers teaching three year olds: Authoritative parenting and adults scaffolding of young children's learning. Developmental Psychology, 24, 832-839.

Portes, P.R., Cuentas, T.E. ve Zady, M. (2000). Cognitive socialization across ethnocultural contexts: Literacy and cultural differences in intellectual performance and parent-child interaction. Journal of Genetic Psychology, 16 (1), 79-99.

Raver, C.C. (1996). Success at cathcing and keeping toddler's attention: An examination of joint attention among low income mothers and their 2 years olds. Early Development and Parenting, 5 (4), 225236.

Robinson, J.B., Burns, B.M. ve Davis, D.W. (2009). Maternal scaffolding and attention regulation in children living in poverty. Journal of Applied Developmental Psychology, 30 (2), 82-91. 
Rogoff, B., Mistry, J., Goncu, A. ve Mosier, C. (1993). Guided participation in cultural activity by Toddlers and Caregivers. Monographs of the Society for Research in Child Development, 58 (8), 5.

Rogoff, B. (1995). Observing sociocultural activity on three planes: participatory appropriation, guided participation, and apprenticeship. J.V. Wertsch, P. Del Rio ve A. Alvarez (Düz.), Sociocultural studies of mind içinde (139-165). NY: Cambridge University Press.

Salonen, P., Lepola, J. ve Vauras, M. (2007). Scaffolding interaction in parent-child dyads: Multimodal analysis of parental scaffolding with task and non-task oriented children. European Journal of Psychology of Education, 22 (1), 77-96.

Smith, K. E., Landry, S. H. ve Swank, P. R. (2000). Does the content of mothers' verbal stimulation explain differences in children's development of verbal and nonverbal cognitive skills?. Journal of School Psychology, 38 (1), 27-49.

Szechter, L.E. ve Liben, L.S. (2004). Parental guidance in preschoolers understanding of spatial-graphic representations. Child Development, 25 (3), 869-885.

Vygotsky, L.S. (1978). Mind in Society. M. Cole, V.Joh-Steiner, S. Scribner ve E. Souberman (Düz.). Massachusetts: Harvard University Press.

Vygotsky, L. S. ve Luria, A. (1994). Tool and symbol in child development. R.Van der Veer ve J. Valsiner (Düz.), The Vygotsky Reader içinde (99-175). Oxford: Basil Blackwell Ltd. 
Wertsch, J. (1997). Vygotsky and the social formation of mind. Cambridge: Harvard University Press.

Wood, D., Bruner, J. ve Ross, G. (1976). The role of tutoring in problem solving. Journal of Child Psychology and Psychiatry, 17, 89-100.

Wood, D., Wood, H. A. ve Middleton, D. J. (1978). An experimental evaluation of four face-to-face teaching strategies. International Journal of Behavioral Development, 1, 131-147. 